Proc. Indian Acad. Sci. (Chem. Sci.), Vol. 102, No. 5, October 1990, pp. 697-703.

(1) Printed in India

\title{
Laser Raman spectroscopic studies on the interaction of drug Dapsone with model membranes
}

\author{
V B KARTHA*, N D PATEL and S VENKATESWARAN \\ Spectroscopy Division, Bhabha Atomic Research Centre, Bombay 400085, India
}

\begin{abstract}
Amphiphilic molecules like model membranes exhibit several special properties because of their ability to undergo co-operative aggregation in aqueous systems. The special properties of such aggregates have made them very important in several applications in industry, basic sciences and advanced technology. To understand the interaction of these systems at a molecular level it is necessary to study several processes. Laser Raman spectroscopy is a convenient technique for gaining information at a molecular level on such systems. In the present paper the applications of laser Raman spectroscopy for the study of these systems are discussed with particular reference to the changes in conformation, identification of structural groups involved in various interactions, arrangement or packing of the amphiphiles in the solid, gel or solution phase, and the effect of additives.
\end{abstract}

Keywords. Laser Raman spectra; Dapsone; model membranes; amphiphilic molecules.

\section{Introduction}

One of the most important factors governing the action of drugs and related materials in biological systems is their interaction with lipids, proteins and membranes. Almost all investigations on such interactions have been carried out by non-spectroscopic methods like differential scanning calorimetry, nuclear magnetic resonance spectroscopy and flourescence. Raman and infrared spectroscopic techniques are well-suited for such studies (Lord and Mendelsohn 1981; Carey 1982; Wong 1984) since they yield information about changes in structure or mobility of individual molecular moieties or degree of binding of characteristic groups in biomolecular systems. But the above methods have been used very little because of experimental difficulties such as low Raman scattering cross-section and absorption due to water in the infrared region. With recent developments in instrumentation such studies are now quite easy and we have been able to carry out infrared and Raman spectral studies on interaction of the drug Dapsone with model membrane systems under various conditions.

\section{Materials and methods}

All materials were obtained from standard sources. Dipalmitoyl phospatidyl choline (DPPC) and dipalmitoyl phosphatidyl ethanolamine (DPPE) were obtained from Sigma, and Dapsone (DDS) from Burroughs Wellcome (India).

\footnotetext{
* For correspondence
} 
The sample of DPPC was first dissolved in GR grade chloroform and the solution evaporated to dryness in a nitrogen stream and then dried under vacuum. Lipid dispersions for the infrared and Raman studies were prepared by mixing the desired amounts of sample and water. In order to obtain proper hydration, the lipid dispersion was repeatedly warmed to about $15^{\circ} \mathrm{C}$ above the melting transition temperature $T m$, and allowed to cool below the Tm before starting the measurements. For the preparation of lipid drug mixture (DPPC + DDS), the drug was dissolved in GR grade methanol and the mixed solution dried under a nitrogen stream and the above process repeated.

Infrared spectra were recorded using a Perkin Elmer Model 180 double beam spectrophotometer with the sample between two barium fluoride windows. The spectra were recorded in the region $4000-1000 \mathrm{~cm}^{-1}$. For infrared spectral studies of membranes a thermostatted cell has been designed for studying the spectra at different temperatures. The phase transitions were monitored by measuring changes in band parameters as a function of temperature. Raman spectra were recorded on a Spex Model 1401 Raman Spectrophotometer using $514.5 \mathrm{~nm} \mathrm{Ar}^{+}$laser excitation. The spectrophotometer has been interfaced to a Wipro PC for efficient data collection and processing. The sample was mounted between two glass plates in a rotating disc sample holder, so that different portions of sample are exposed to laser radiation thereby avoiding sample reaction and decomposition. Spectral slitwidths of $2-4 \mathrm{~cm}^{-1}$ and laser powers of $50-200 \mathrm{~mW}$ at the sample end were used depending on signal intensity. All spectra have been recorded in the step/scan mode. For this, the spectral range of scan, the starting position, step size and time of signal collection at each step are given to the computer. The computer then positions the spectrometer to the starting point and collects the counts at each step, at the desired intervals. Thus the entire process of recording a spectrum is done under computer control (Ravindranath

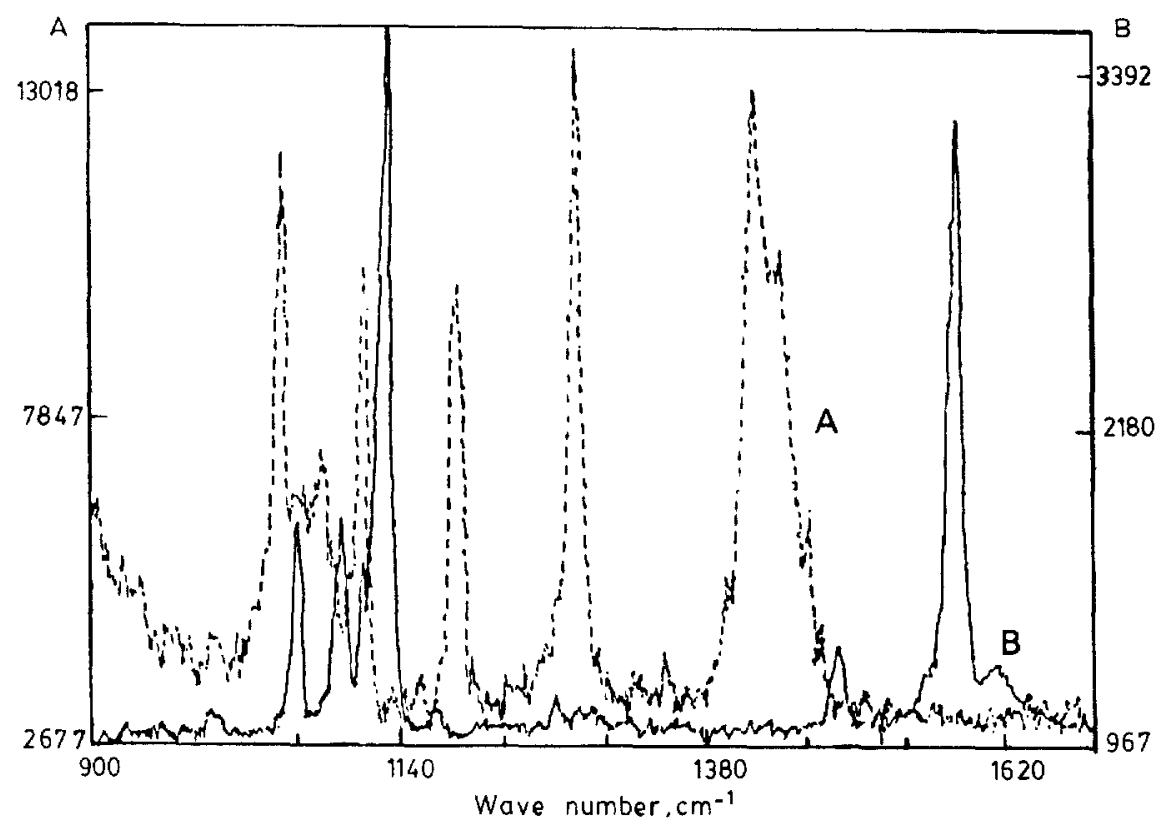

Figure 1. Laser Raman spectra of (A) Dapsone and (B) DPPC in the region $900-1700 \mathrm{~cm}^{-1}$. 
1988). All data processing like locating a peak and finding peak position, signal averaging, scale expansion, spectral normalisation etc., is also done by the computer. Synthetic and difference spectra are generated for the purpose of comparison and spectral shift measurements.

\section{Results and discussions}

The Raman spectra of DPPC, DPPC + Dapsone and Dapsone for the entire region $100-3600 \mathrm{~cm}^{-1}$ have been recorded. Typical spectra of DPPC and Dapsone in the region $900-1700 \mathrm{~cm}^{-1}$ are shown in figure 1 . Table 1 shows the frequencies for the bands of interest. In figure 2 we have compared the spectrum of the mixture of DPPC and Dapsone with the synthetic spectrum. Spectra of DPPC and Dapsone have been recorded and normalised to the $1300 \mathrm{~cm}^{-1}$ band of DPPC and the $1600 \mathrm{~cm}^{-1}$ band of Dapsone, respectively, such that the intensities of the mixture and the synthetic spectrum become comparable. The two strong lines at 1131 and $1067 \mathrm{~cm}^{-1}$ are assigned to the skeletal optical modes of all trans conformers. Gaber and Peticolas (1977) have used the feature near $1130 \mathrm{~cm}^{-1}$ to extract quantitative information

Table 1. Frequencies $\left(\mathrm{cm}^{-1}\right)$ of DPPC + Dapsone, DPPC and Dapsone.

\begin{tabular}{|c|c|c|}
\hline DPPC + Dapsone & DPPC & Dapsone \\
\hline 1065 & $\begin{array}{l}1067 \\
\text { skeletal optical } \\
\text { mode, trans }\end{array}$ & \\
\hline 1074 & & $\begin{array}{l}1077 \\
C-H \text { in-plane bending }\end{array}$ \\
\hline 1107 & $\begin{array}{l}1095 \\
\text { gauche isomer }\end{array}$ & $\mathrm{NH}_{2}$ rock and $\mathrm{CH}$ bending \\
\hline 1131 & $\begin{array}{l}1131 \\
\text { skeletal optical } \\
\text { mode, trans }\end{array}$ & \\
\hline 1142 & & $\begin{array}{l}1141 \\
\mathrm{C}-\mathrm{N} \text { str, }+\mathrm{SO}_{2} \text { sym. str. }\end{array}$ \\
\hline 1300 & $\begin{array}{l}1301 \\
\mathrm{C}-\mathrm{H} \text { bending }\end{array}$ & \\
\hline 1439 & 1439 & \\
\hline 1447 & $\begin{array}{l}1451 \\
\mathrm{C}-\mathrm{H} \text { bending }\end{array}$ & \\
\hline 1600 & & $\begin{array}{l}1601 \\
C-C \text { bending }\end{array}$ \\
\hline 2841 & $\begin{array}{l}2842 \\
\text { C-H methylene } \\
\quad \text { sym. str. }\end{array}$ & \\
\hline 2877 & $\begin{array}{l}2878 \\
\mathrm{C}-\mathrm{H} \text { methylene } \\
\quad \text { asym. str. }\end{array}$ & \\
\hline 2899 & 2894 & \\
\hline 2923 & $2927 \mathrm{H}$ & \\
\hline
\end{tabular}

Abbreviations: asym. - asymmetric; sym. - symmetric; str. - stretching 


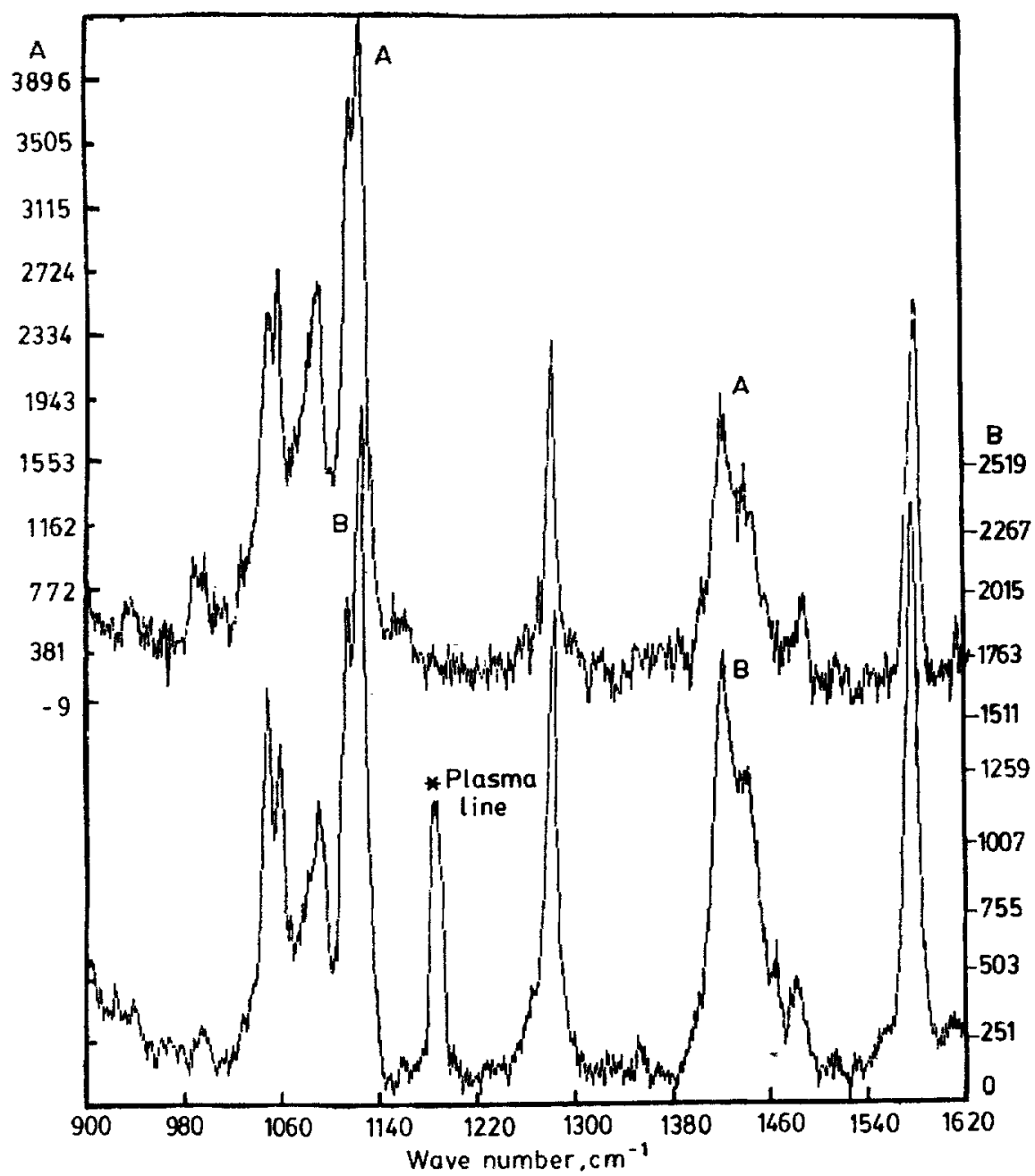

Figure 2. Laser Raman spectra of (A) DPPC + Dapsone (mixture) and (B) DPPC + Dapsone (synthetic).

regarding lipid behaviour. They propose that the mode near $1130 \mathrm{~cm}^{-1}$ be attributed to the sum of intensities from individual all-trans chain segments. Our studies also show that there is a considerable change in the $1100-1300 \mathrm{~cm}^{-1}$ region. The band at $1600 \mathrm{~cm}^{-1}$ also shows noticeable change after the interaction with the drug. This is clearer from the difference spectrum shown in figure 3 . The differential form in the difference spectrum indicates a definite shift in the ring mode. If there had been no change between the mixture (DPPC + DDS) and the synthetic spectrum then it would have resulted in a simple background. But figure $3 \mathrm{~B}$ shows some spectral features in the $900-1300 \mathrm{~cm}^{-1}$ region. The intensity of the gauche mode at about $1095 \mathrm{~cm}^{-1}$ increases considerably, presumably due to increase in the fraction of gauche conformation. Also there seems to be some increase in the intensity in $\mathrm{CH}_{2}$ wag $\left(1067 \mathrm{~cm}^{-1}\right)$ and in mixed vibrational mode $\mathrm{C}-\mathrm{C}$ stretch and $\mathrm{CH}_{2}$ rock $\left(1131 \mathrm{~cm}^{-1}\right)$, 


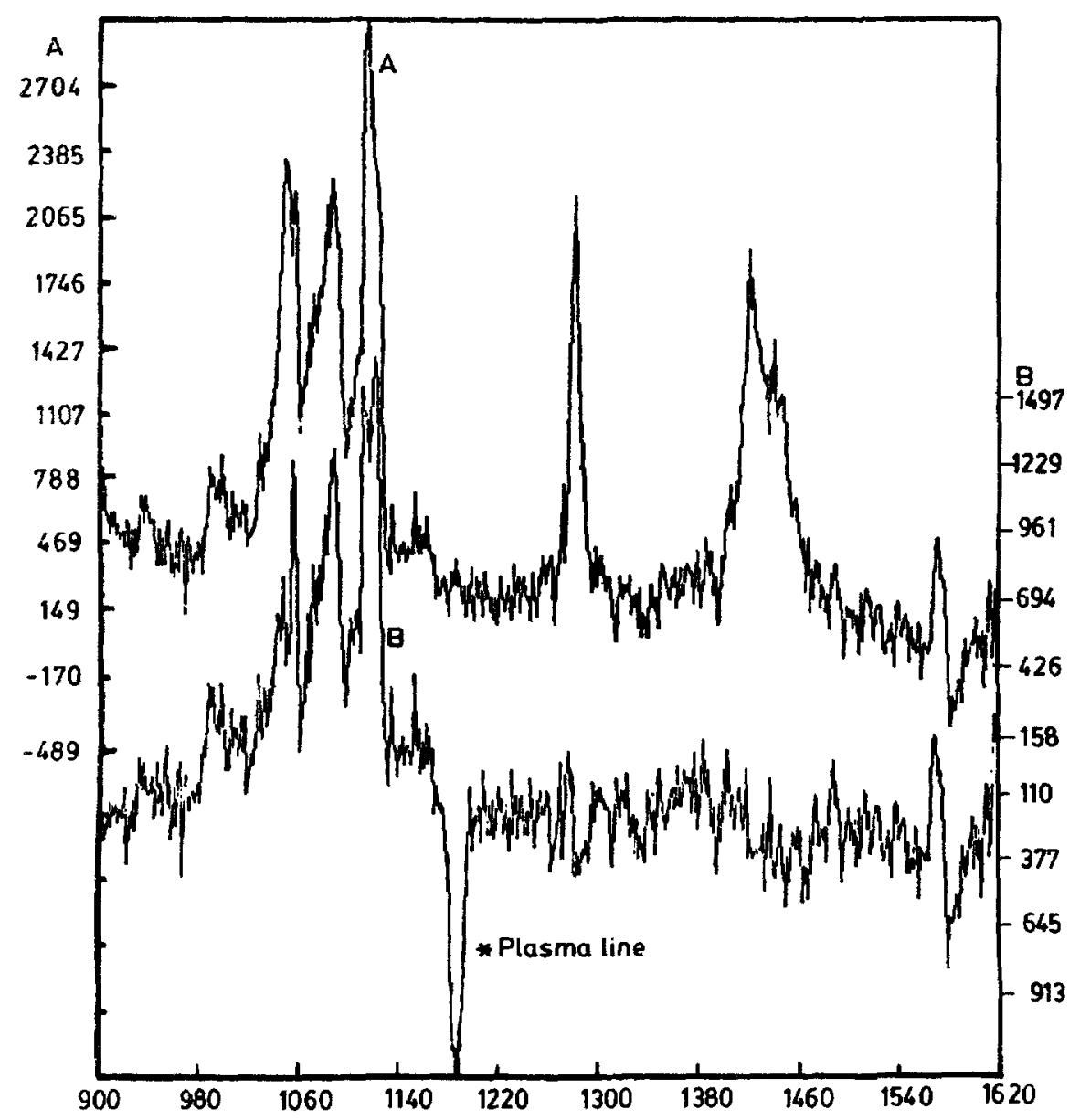

Figure 3. Difference spectra of (A) $\{$ DPPC + Dapsone $\}-$ Dapsone and (B) $\{\mathrm{DPPC}+$ Dapsone $\}-D P P C-D a p s o n e$ in the region $900-1600 \mathrm{~cm}^{-1}$.

whereas ring mode at $1600 \mathrm{~cm}^{-1}$ (DDS) and $\mathrm{CH}_{2}$ twist at $1300 \mathrm{~cm}^{-1}$ (DPPC) remain unaffected. Similar changes are seen in the $\mathbf{C}-\mathbf{H}$ region of DPPC where both the symmetric and antisymmetric $\mathrm{C}-\mathrm{H}$ stretching vibrations have shifted to lower frequencies as shown in figure 4. The changes in the ring vibrational mode and $\mathrm{NH}_{2}$ rock of Dapsone and shifting to lower frequencies of the $\mathrm{C}-\mathrm{H}$ stretching bands of DPPC indicate that the Dapsone is held through the $\mathrm{NH}_{2}$ end to DPPC.

A considerable increase in intensity in the $1060-1130 \mathrm{~cm}^{-1}$ region $\left(1107 \mathrm{~cm}^{-1}\right.$ band) indicates that the introduction of the drug stabilises the lower orthorhombic or monoclinic lattice.

The above conclusion is confirmed by the temperature behaviour studies of the $\mathrm{C}-\mathrm{H}$ stretching region. A plot of frequency verses temperature for the $\mathrm{C}-\mathrm{H}$ stretching band of DPPC and DPPC + DDS band is shown in figure 5 . The pretransition seems to have disappeared from the mixture (DPPC + DDS) and only the melting transition seems to be taking place after the interaction with the drug. 


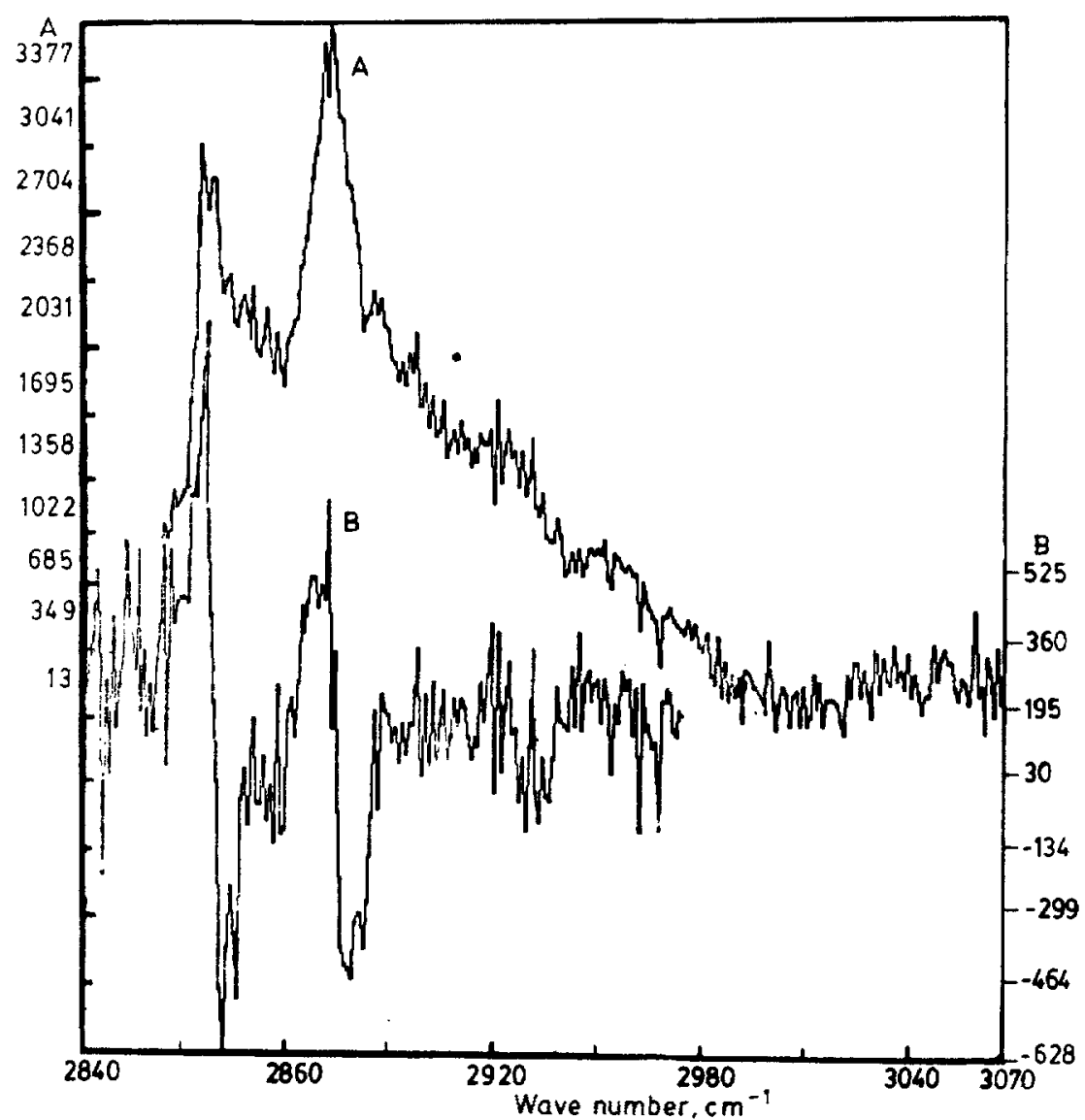

Figure 4. Difference spectra of (A) DPPC + Dapsone and (B) $\{$ DPPC + Dapsone $\}-D P P C$ in the region $2800-3100 \mathrm{~cm}^{-1}$.

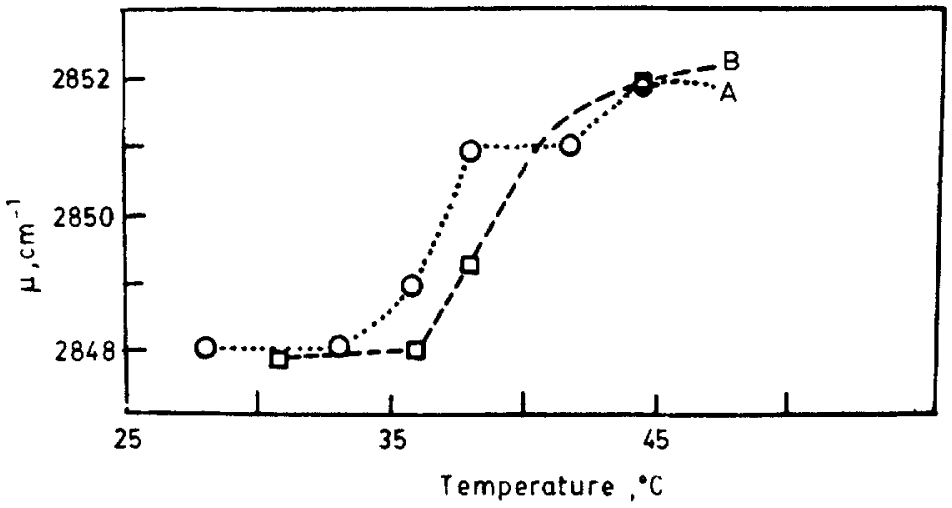

Figure 5. The premelting and melting transition of DPPC without (A) and with (B) Dapsone. 


\section{References}

Carey P R 1982 in Biochemical applications of Raman and resonance Raman spectroscopy (New York: Academic Press) pp. 208-233

Gaber B P and Peticolas W C 1977 Biochim. Biophys. Acta 465260

Lord R C and Mendelsohn R 1981 in Membrane spectroscopy (ed.) E Grell (Berlin: Springer) pp. 374-436

Ravindranath S V G 1988 Data acquisition and control of a Raman spectrometer using an IBM-PC compatible Personal Computer, ISAS National Symposium on analytical spectroscopy including hyphenated techniques, Hyderabad

Wong P T T 1984 Annu. Rev. Biophys. Bioeng. 131 